Lih, H., King, 'T. E., Higgins, H., Baumann, C. A. \& Strong, F. M. (195 r). J. Nutr. 44, 36r . Mason, K. E. (1944). Vitam. \& Horm. 2, 107.

Olcott, H. S. \& Mattill, H. A. (1937). F. Nutr. 14, 305.

Peters, J. P. \& Van Slyke, D. D. (1932). Quantitative Clinical Chemistry, Vol. 2, p. 668. London: Baillière, Tindall and Cox.

Wu, H. (1922a). J. Biochem., Tokyo, 2, 173.

Wu, H. (1922b). Y. Biochem., Tokyo, 2, I89.

\title{
The Effect of Antibiotics on the Metabolism of Nicotinic Acid, Biotin and Folic Acid in Rats
}

\author{
By S. HALEVY, E. J. DIAMANT AND K. GUGGENHEIM \\ Laboratory of Nutrition, Department of Biochemistry, Hebrew University- \\ Hadassah Medical School, ferusalem, Israel
}

(Received 6 August 1954)

It has previously been shown (Guggenheim, Halevy, Hartmann \& Zamir, 1953) that oral administration of penicillin, aureomycin (chlortetracycline), streptomycin or oxytetracycline (terramycin) causes a marked stimulation of gruwth in rats fed on diets low in riboflavin or in pantothenic acid. A similar effect was observed with penicillin and oxytetracycline added to a diet low in thiamine, whereas the inclusion of these antibiotics in a completely vitamin-supplemented diet had no growth-promoting effect. Growth stimulation was generally associated with a higher liver level and increased urinary excretion of these vitamins. Since subcutaneous injections of antibiotics had no effect on growth or on the accumulation of these vitamins in the liver, it was concluded that the observed sparing effect of the antibiotics on the requirement of young rats for certain B-vitamins is mainly due to alterations in the intestinal flora.

The vitamins studied in our previous work are not synthesized in the rat intestine in sufficient amounts and they must, therefore, be provided in the food. This paper presents the results obtained with nicotinic acid, biotin and folic acid, which are synthesized abundantly by the rat's intestinal flora.

\section{METHODS}

Male rats weighing $40-50 \mathrm{~g}$ were placed on the $18 \%$ casein diet described previously (Guggenheim et al. 1953). In the experiments with nicotinic acid the level of casein in the diet was reduced, half of it being replaced by maize starch. The diet of the rats that received $2 \%$ succinylsulphathiazole in the diet was fortified with $19 \mathrm{mg}$ menaphthone, $40 \mathrm{mg} p$-aminobenzoic acid and $200 \mathrm{mg}$ inositol $/ \mathrm{kg}$. Within each experiment the food intake of treated animals was equalized with that of their controls. The antibiotics aureomycin, penicillin, oxytetracycline and streptomycin were each fed to a different group, being incorporated in the ration at a level of $50 \mathrm{mg} / \mathrm{kg}$ diet.

At the end of the $3^{\text {rd }}$ and 5 th weeks of the experiment urine was collected from each rat for 3 days, and the amounts of $N^{\prime}$-methylnicotinamide, biotin, folic acid and 
citrovorum factor $(\mathrm{CF})$ were determined in it. Since similar results were obtained for the two collection periods, the figures given in Tables $\mathrm{I}-3$ are the combined results. At the end of the $5^{\text {th }}$ week all rats were killed and the amounts of biotin, folic acid and $\mathrm{CF}$ determined in the caecum contents. The livers were examined for content of the same vitamins and of nicotinic acid.

The vitamins and their metabolites studied were determined by the following methods: nicotinic acid by the cyanogen-bromide method (Sweeney, 195I); $N^{\prime}-$ methylnicotinamide by that of Huff \& Perlzweig (1947); biotin and folic acid with Lactobacillus arabinosus and Streptococcus faecalis, respectively (Association of Vitamin Chemists, 1951); CF with Leuconostoc citrovorum by the method of Sauberlich \& Baumann (1948). Synthetic citrovorum factor (Leucovorin) in the form of the hydrated barium salt was used as standard. Liver folic acid and CF were extracted as described by Dietrich, Monson, Gwoh \& Elvehjem (1952) and then determined by the methods mentioned above.

\section{RESULTS}

Nicotinic acid. None of the antibiotics studied was found to stimulate growth of rats maintained on a diet providing $90 \mathrm{~g}$ casein and $50 \mathrm{mg}$ nicotinic acid $/ \mathrm{kg}$ diet (Table I); nor was the excretion of $N^{\prime}$-methylnicotinamide in urine affected by the administration of antibiotics. The level of nicotinic acid in the liver, however, was increased by aureomycin and oxytetracycline; streptomycin and penicillin had no effect.

Table I. Mean values with their standard errors for increase in weight, $N^{\prime}$-methylnicotinamide content of urine and nicotinic-acid content of liver of pair-fed rats given a dietary antibiotic supplement

\begin{tabular}{|c|c|c|c|c|c|}
\hline \multirow{2}{*}{$\begin{array}{l}\text { No. of } \\
\text { rats }\end{array}$} & \multirow[b]{2}{*}{ Antibiotic } & \multirow{2}{*}{$\begin{array}{c}\text { Weight } \\
\text { increase } \\
\text { in } 5 \text { weeks } \\
(\mathrm{g})\end{array}$} & \multirow{2}{*}{$\begin{array}{l}\text { Excretion of } \\
N^{\prime} \text {-methyl- } \\
\text { nicotinamide } \\
\text { in urine } \\
\text { ( } \mu \mathrm{g} / \text { day })\end{array}$} & \multicolumn{2}{|c|}{ Nicotinic acid in liver } \\
\hline & & & & $\mu \mathrm{g} / \mathrm{g}$ & $\mu \mathrm{g}$ \\
\hline 12 & None & $49 \pm 4 \cdot 4$ & $50 \pm 3 \cdot 6$ & $110 \pm 8 \cdot 3$ & $391 \pm 33$ \\
\hline 12 & Streptomycin & $56 \pm 2 \cdot 3$ & $53 \pm 7 \cdot 1$ & $110 \pm 4.0$ & $440 \pm 21$ \\
\hline 12 & Oxytetracycline & $57 \pm 3.8$ & $56 \pm 5 \cdot 8$ & $112 \pm 3.5$ & $500 \pm 18 * *$ \\
\hline 6 & Aureomycin & $5^{2} \pm 4 \cdot 9$ & $35 \pm 7 \cdot 2$ & $148 \pm 5.5^{* * *}$ & $560 \pm 29 * * *$ \\
\hline 6 & Penicillin & $4^{8} \pm 7 \cdot 3$ & $47 \pm 5 \cdot 2$ & $133 \pm 8.9$ & $462 \pm 25$ \\
\hline
\end{tabular}

Biotin. The inclusion of antibiotics in the diet produced various effects on biotin metabolism (Table 2). Aureomycin and penicillin were without any influence on the biotin level in urine, caecum contents and liver; oxytetracycline depressed the biotin content of the caecum; and streptomycin reduced the urinary excretion and caecum level of that vitamin. But neither of the last two antibiotics affected the biotin content of the liver.

In further experiments biotin deficiency was produced by incorporating $2 \%$ succinylsulphathiazole in the diet. The drug significantly depressed growth and biotin levels in urine, caecum contents and liver. Aureomycin was found to be without effect 

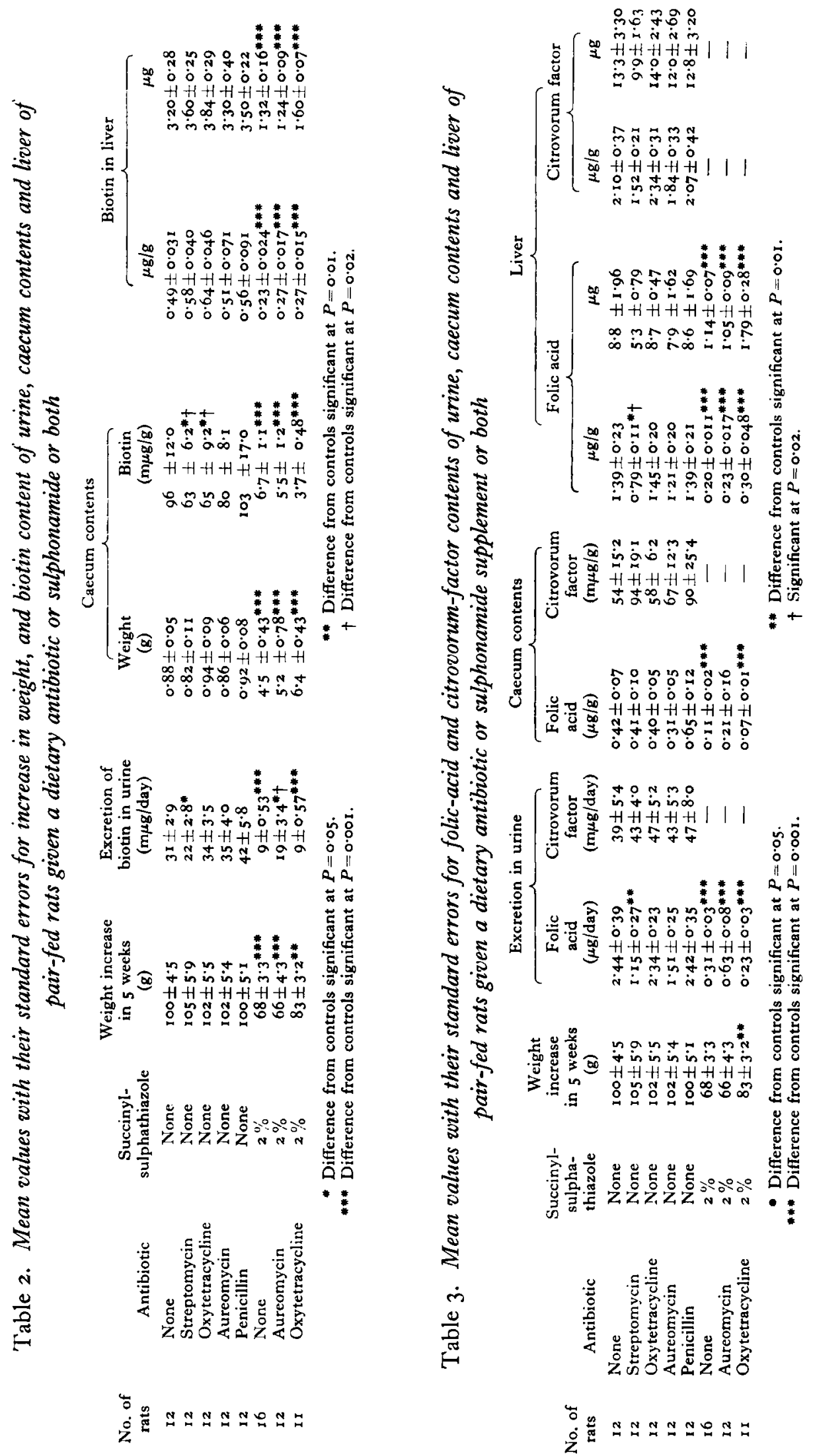
on growth and biotin content of caecum and liver in treated rats, but it significantly increased the urinary excretion of this vitamin. Oxytetracycline, however, did not affect the level of the vitamin in urine, caecum or liver, but had a highly significant growth-promoting effect.

Prolonged administration of succinylsulphathiazole caused a considerable enlargement of the caecum, whereas treatment with the antibiotics did not affect caecum weight. It is, however, noteworthy, that the sulphonamide led to an absolute as well as a relative decrease in the biotin content of the caecum.

Folic acid. In our experiments with folic acid we studied the effect of antibiotics on both folic acid and CF in urine, caecum and liver (Table 3). Whereas the urinary excretion of folic acid was thirty- to sixty-fold higher than that of CF, the reverse was found in the liver, where more CF than folic acid was present. Streptomycin significantly reduced urinary excretion and liver level of folic acid, but was without any effect on its amounts in the caecum. No effect was obtained on the quantities of $\mathrm{CF}$ in urine, caecum or liver. The other antibiotics did not appear to have any effect on the metabolism of folic acid or CF in normal rats. Rats deficient in folic acid and treated with sulphonamide exhibited significantly lower concentrations of urinary, caecal and liver folic acid. Since the treatment with succinylsulphathiazole enlarged the caecum, greater total amounts of folic acid were found in the caecums of these rats. Aureomycin significantly increased the urinary excretion and oxytetracycline the liver concentration of folic acid in sulphonamide-treated rats.

\section{DISCUSSION}

Whereas the four antibiotics studied by us exhibited a sparing action on riboflavin and pantothenic acid, and both penicillin and oxytetracycline on thiamine as well (Guggenheim et al. 1953), no such clear-cut effects could be observed on the vitamins examined in the study recorded here. There was an increase of liver nicotinic acid due to oxytetracycline and aureomycin, and a rise of biotin and folic-acid excretion in the urine of sulphonamide-treated rats given aureomycin. Growth stimulation and increase in liver folic acid under these conditions were observed with oxytetracycline. Aureomycin and oxytetracycline appear, therefore, to exhibit a certain sparing effect on nicotinic acid and in sulphonamide-induced deficiency on folic acid as well. Under these conditions aureomycin also shows a sparing action on biotin. But these sparing effects seem to be much weaker than those observed for riboflavin, pantothenic acid and thiamine. Streptomycin, however, decreased urinary excretion and liver concentration of folic acid and the biotin contents of caecum and urine. Streptomycin increases, therefore, the requirements for these two vitamins. These findings indicate that each antibiotic exerts a distinct effect on the economy of the different B-vitamins studied.

The effect of orally administered antibiotics on the metabolism of nicotinic acid, biotin and folic acid has already been studied with various techniques and on different animals. Aureomycin has been reported to exert in chicks a sparing action on nicotinic acid and folic acid (Biely \& March, I95 I Monson, Harper, Winje, Elvehjem, Rhodes \& Sarles, 1954), to be without effect on the requirement for nicotinic acid 
(Nelson \& Scott, 1952) and to depress growth in mild folic-acid deficiency (Briggs, Spivey \& Ortiz, 1953). Schwarz \& Sebrell (1951) have shown that addition of aureomycin to a stock diet increased the concentration of $\mathrm{CF}$ and decreased that of folic acid in the rat caecum. Correspondingly, more CF was found in the livers of rats treated with the antibiotic. We were not able to confirm this shift from folic acid to increased CF in animals receiving aureomycin or any other antibiotic. Waisman, Green, Munoz, Ramenchik \& Richmond (195I) produced folic-acid deficiency in rats by feeding sulphonamide drugs. Dietary aureomycin was found to be ineffective in counteracting these drugs. Also, in our experiments we only noted a slight effect of aureomycin or oxytetracycline in overcoming sulphonamide-induced biotin and folic-acid deficiencies.

Penicillin has been reported to increase the chick's requirement for nicotinic acid, but to spare biotin and folic acid (Coates, Dickinson, Harrison \& Kon, 195 I). Waibel, Sunde, Baumann \& Cravens (I952) observed that the addition of penicillin to the feed increased the biotin and folic-acid contents of hen's eggs. Similarly, penicillin was found to stimulate the growth of chicks fed on diets containing limiting amounts of folic acid (Monson et al. I954).

Oxytetracycline added to a biotin-free diet diminished the synthesis of biotin, as shown by the excretion of the vitamin (Ham \& Scott, 1953). Our finding with this antibiotic was a depression of biotin concentration in the caecum only, whereas the levels in urine and liver as well as the growth of the animals were not affected.

Emerson \& Smith (1945) succeeded in inducing a biotin deficiency in rats by adding streptomycin to a purified diet. This also led to a lowering in the amount of biotin synthesized by the intestinal flora. We were able fully to confirm this effect of the antibiotic on intestinal synthesis of biotin. Administration of streptomycin decreased the biotin concentration in both urine and caecum, as well as the folic-acid contents of liver and urine.

\section{SUMMARY}

I. The effect of dietary aureomycin, oxytetracycline, penicillin and streptomycin upon the metabolism of nicotinic acid, biotin and folic acid has been studied in rats.

2. Aureomycin increased the amount of nicotinic acid in liver, and in rats treated with sulphonamide it enhanced the excretion of biotin and folic acid in urine.

3. Oxytetracycline increased the concentration of nicotinic acid in the liver. In rats treated with sulphonamide it stimulated growth and raised the liver level of folic acid.

4. Penicillin was without any effect.

5. Streptomycin reduced urinary excretion and liver concentration of folic acid and the biotin contents of caecum and urine.

6. No effect of any antibiotic was noted on the conversion of folic acid into citrovorum factor.

7. Under our experimental conditions aureomycin seemed to exert a weak sparing action on nicotinic acid, folic acid and biotin, and oxytetracycline on nicotinic acid and folic acid. In contrast, streptomycin appeared to increase the requirement of rats for biotin and folic acid. 
The antibiotics used in this study were generously supplied by Lederle Laboratories Inc. (aureomycin), Chas. Pfizer and Co. (Terramycin brand of oxytetracycline), E. R. Squibb and Sons (streptomycin) and Teva, Middle East Chemical and Pharmaceutical Co., Jerusalem, Israel (penicillin). Leucovorin was supplied by Lederle Laboratories Inc., by courtesy of $\mathrm{Dr} \mathrm{T}$. H. Jukes.

\section{REFERENCES}

Association of Vitamin Chemists (1951). Methods of Vitanin Assay, 2nd ed. New York: Interscience Publishers Inc.

Biely, J. \& March, B. (1951). Science, 114, 330.

Briggs, G. M., Spivey, M. R. \& Ortiz, L. O. (1953). F. Nutr. 51, 355.

Coates, M. E., Dickinson, C. D., Harrison, G. F. \& Kon, S. K. (195I). Biochem. J. 49, 1xviii.

Dietrich, L. S., Monson, W. J., Gwoh, H. \& Elvehjem, C. A. (1952). J. biol. Chem. 194, 549.

Emerson, G. A. \& Smith, D. G. (1945). F. Pharmacol. exp. Ther. 85, 232.

Guggenheim, K., Halevy, S., Hartmann, I. \& Zamir, R. (1953). F. Nutr. 50, 245.

Ham, W. E. \& Scott, K. W. (1953). Y. Nutr. 51, 423.

Huff, J. W. \& Perlzweig, W. A. (1947). F. biol. Chem. 167, 157.

Monson, W. J., Harper, A. E., Winje, M. E., Elvehjem, C. A., Rhodes, C. A. \& Sarles, W. B. (1954). J. Nutr. 52, 627 .

Nelson, T. S. \& Scott, H. M. (1952). Poult. Sci. 31, 929.

Sauberlich, H. E. \& Baumann, C. A. (1948). J. biol. Chem. 176, 165.

Schwarz, K. \& Sebrell, W. H. (1951). Fed. Proc. Io, 394.

Sweeney, J. P. (1951). J. Ass. off. agric. Chem. 34, 380.

Waibel, P. E., Sunde, M. L., Baumann, C. A. \& Cravens, W. W. (1952). Poult. Sci. 31, 938.

Waisman, H. A., Green, M., Munoz, J. C., Ramenchik, A. \& Richmond, J. B. (195 I). Proc. Soc. exp. Biol., N.Y., 76, 384 . 